\title{
Análise Computacional da Força de Empuxo em Hélices de um Agitador de Resíduos
}

\author{
Computational Analysis of thrust force in propellers of a residues stirrer
}

\section{Anderson José Antonietti ${ }^{1}$ (D) orcid.org/0000-0002-7437-529X}

\author{
Erick Rezler 2 (b) orcid.org/0000-0002-2503-8676 \\ ${ }^{1}$ Instituto Federal de Santa Catarina - Câmpus Jaraguá do Sul - Rau, Santa Catarina, Brasil, \\ 2 Empresa Archea Biogás América Latina Ltda. \\ E-mail do autor principal: Anderson José Antonietti anderson.jose@ifsc.edu.br
}

\section{Resumo}

Este trabalho apresenta uma análise computacional da força de empuxo em hélices de um agitador de resíduos. Dentre os principais benefícios proporcionados pelo agitador de resíduos na geração do biogás, está a capacidade de evitar que o gás carbônico $\left(\mathrm{CO}_{2}\right)$, produzido na biodigestão, forme bolhas estacionárias no afluente e acabe por dificultar a ação das bactérias, o que diminui a velocidade do processo. Teoricamente, a hélice que produzir uma maior força de empuxo proporcionará também uma melhor misturação dos resíduos e, consequentemente, aumento na produção de biogás. A obtenção da força de empuxo das hélices foi realizada através de simulação computacional, para uma rotação da hélice de $300 \mathrm{rpm}$. De acordo com os resultados obtidos, a hélice com ângulo de inclinação das pás de $25^{\circ}$ apresentou uma força de empuxo $32 \%$ maior em comparação com a outra hélice, com ângulo de $20^{\circ}$. Assim, foi constatado que a hélice com maior ângulo de inclinação das pás seria a mais indicada para a aplicação no tanque biodigestor.

Palavras-Chave: Simulação; Biogás; Biodigestor.

\begin{abstract}
This work presents a computational analysis of the thrust force in propellers of a residues stirrer. Among the main benefits provided by the residues stirrer in the generation of biogas is the ability to prevent carbon dioxide $\left(\mathrm{CO}_{2}\right)$, produced in the biodigestion, form stationary bubbles in the affluent and eventually hampering the action of bacteria, which slows down the process. Theoretically, the propeller which produces a greater thrust force will also provide better mixing of the residues and, consequently, an increase in biogas production. The propeller thrust force was obtained by computer simulation, for a propeller rotation of $300 \mathrm{rpm}$. According to the results obtained, the propeller with tilt angle of the blades of $25^{\circ}$ presented a force of thrust $32 \%$ greater in comparison with the other propeller, with angle of $20^{\circ}$. Thus, it was found that the propeller with greater tilt angle of the blades would be the most indicated for the application in the biodigestor tank.
\end{abstract}

Key-words: Simulation; Biogas; Biodigestor. 


\section{INTRODUÇÃO}

O biogás é um elemento versátil entre as energias renováveis e pode ser usado como fonte de eletricidade, calor e como substituto do gás natural. Segundo Bueno [1], o biogás tem sua origem na digestão anaeróbia de material orgânico, que é um processo de estabilização biológica no qual um consórcio de diferentes tipos de microrganismos, na ausência de oxigênio molecular, promove a transformação de compostos orgânicos complexos em produtos mais simples como o metano $\left(\mathrm{CH}_{4}\right)$ e o gás carbônico $\left(\mathrm{CO}_{2}\right)$. De acordo com este autor, os biodigestores são constituídos por duas partes distintas: câmara de fermentação e gasômetro. A câmara de fermentação dispõe de um agitador que tem a função de evitar que $0 \mathrm{CO}_{2}$, produzido na biodigestão, forme bolhas estacionárias no material orgânico diluído. A ocorrência de tais bolhas dificulta a ação das bactérias, diminuindo a velocidade do processo.

Além disso, de acordo com Pellizzer [2], a maioria dos modelos de biodigestores utilizados atualmente no Brasil não possuem agitação automática da biomassa, ocasionando uma variação significativa na temperatura interna da câmara de fermentação. Esta variação de temperatura prejudica a biodigestão, devido aos microorganismos serem sensíveis às variações acima de $2^{\circ} \mathrm{C}$ no período de um dia, paralisando a produção do biogás. Deste modo, percebe-se que a presença de agitadores na câmara de fermentação é indispensável para aumentar a velocidade do processo de produção do biogás. Porém, apenas a presença do agitador não é suficiente, é necessário que o mesmo produza uma força de empuxo capaz de promover a misturação eficiente dos resíduos. Assim, o objetivo deste trabalho é apresentar uma análise computacional da força de empuxo gerada por hélices de um agitador de resíduos.

\section{FUNDAMENTAÇÃO TEÓRICA}

Como em outros dispositivos de propulsão, uma hélice produz empuxo por transmitir uma quantidade de movimento linear ao fluido [3]. Em geral, quanto maior o diâmetro da hélice menor a rotação necessária para o empuxo desejado, ou seja, um navio com hélice de grande dimensão operará a mais baixa rotação, por outro lado, maior será o torque necessário para o movimento da hélice. Segundo Pinheiro [4], quanto maior o empuxo produzido maior será o risco de cavitação da hélice.

Considere o modelo unidimensional, para o escoamento idealizado através de uma hélice, mostrado na Figura 1.

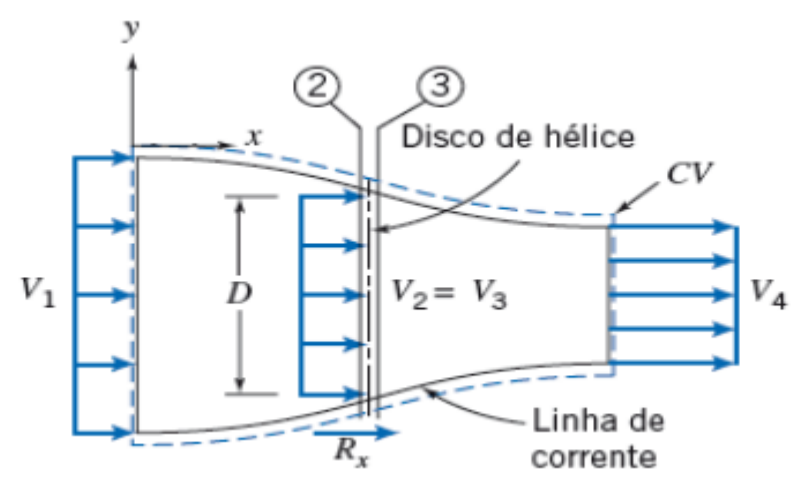

Figura 1: Volume de controle utilizado para analisar uma hélice idealizada.

Fonte: Adaptado [3].

Nesse caso, a hélice real é substituída conceitualmente por um disco atuador ou disco de hélice delgado. Dessa forma, pode-se obter a força de empuxo $\left(F_{T}\right)$ na hélice como o produto da diferença de pressões a jusante $\left(p_{3}\right)$ e a montante $\left(p_{2}\right)$ da hélice com a área do disco $\left(A_{d}\right)$, conforme mostrado na Equação 1.

$$
F_{T}=\left(p_{3}-p_{2}\right) A_{d}
$$

A Equação 2 apresenta a vazão mássica $(\dot{m})$ produzida pela hélice que é determinada pelo produto entre a massa específica do fluido $\rho$ $\left[\mathrm{kg} / \mathrm{m}^{3}\right]$, a velocidade média $V[\mathrm{~m} / \mathrm{s}]$ e a área da seção transversal $A_{t r}\left[\mathrm{~m}^{2}\right]$.

$$
\dot{m}=\rho \cdot V \cdot A_{t r}
$$

Para a obtenção desses valores computacionalmente, fez-se uso das equações de conservação de massa e da quantidade de movimento. Essas equações são responsáveis por garantir que os fenômenos envolvidos no processo sejam corretamente analisados pelo software. Para isso, todo o sistema em estudo deve ser dividido em pequenas partes, o que é denominado de malha. Nas análises envolvendo escoamento de fluidos, o método normalmente 
utilizado é o Método de Volumes Finitos (MVF). As equações governantes do problema são aplicadas e resolvidas para cada elemento da malha várias vezes até que haja a convergência de resultados em todo o sistema.

\section{METODOLOGIA}

A determinação da força de empuxo em hélices envolve algumas variáveis que apenas são possíveis de se obter experimentalmente, ou então, com o auxílio da simulação numérica. A geometria da hélice em estudo apresenta o ângulo de inclinação das pás igual a $20^{\circ}$ e, para que seja possível realizar a análise computacional, a geometria deve passar por um processo de preparação no software SolidWorks removendo-se da mesma recursos que oneram a simulação. A Figura 2 apresenta a geometria da hélice antes e após a preparação.

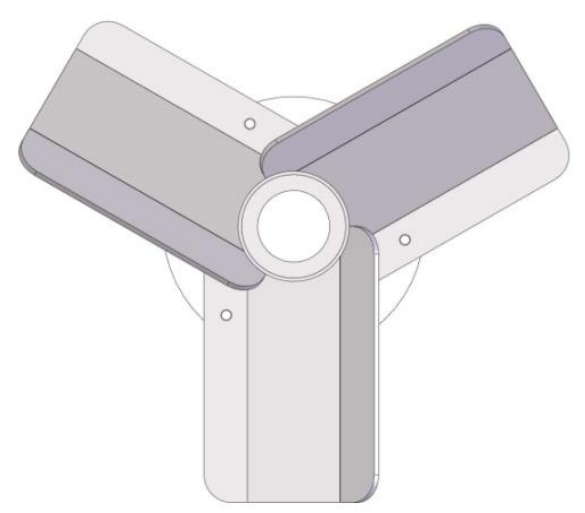

(a)

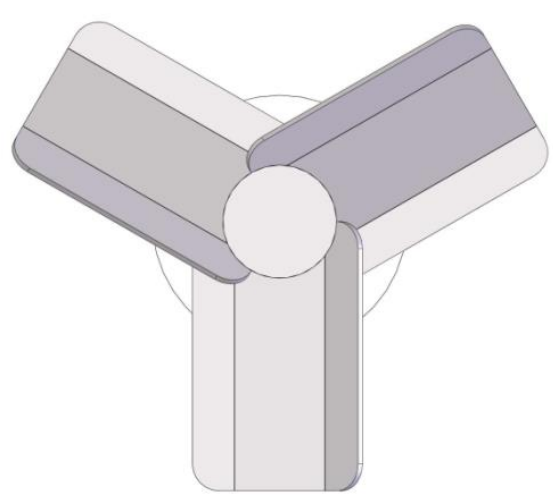

(b)

Figura 2: Geometria da hélice antes (a) e depois (b) do processo de preparação. Fonte: Os Autores.

É necessário também estabelecer um conduto que englobe a hélice e permita a obtenção dos valores desejados. Este conduto deverá ser longo o suficiente para impedir que haja recirculação de fluido na saída do mesmo, caso contrário os resultados da simulação estarão comprometidos. O diâmetro, por sua vez, deverá ser pouco maior que o da hélice a fim de permitir a simulação de sua rotação e capturar a força de empuxo que ocorre axialmente à hélice. Assim, o comprimento total do duto foi definido em $3 \mathrm{~m}$ e o diâmetro do duto em $0,55 \mathrm{~m}$, sendo que a hélice fica posicionada no centro do mesmo, conforme a Figura 3.

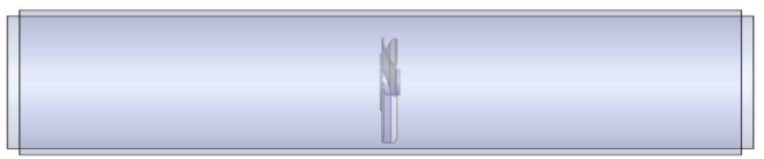

(a)

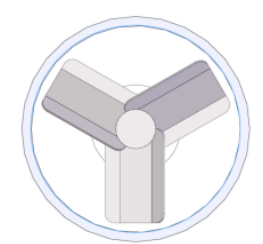

(b)

Figura 3: Vista lateral (a) e frontal (b) do duto utilizado nas análises.

Fonte: Os Autores.

Definidas as dimensões do sistema, foi iniciado o procedimento para a análise computacional utilizando o módulo Flow Simulation, presente no próprio software SolidWorks, e que faz uso do MVF.

A malha computacional empregada é formada por volumes quadriláteros. A partir desta condição foi realizado um estudo de malha considerando os níveis pré-definidos pelo Flow Simulation. Esses níveis visam facilitar 0 processamento da simulação, pois apresentam configurações padrão de tamanho de malha específica para cada nível. Dentre as opções disponíveis, foram analisados os níveis de 5 a 8 , sendo a malha de nível 5 a mais grosseira e a malha de nível 8 a mais refinada.

Por se tratar de um escoamento gerado por uma hélice, ou seja, totalmente caótico, foi necessário aplicar um modelo de turbulência para capturar tais efeitos. Nesse caso, o software apresenta apenas duas opções de modelos de turbulência, Turbulence Energy and Dissipation (TED), também conhecido como $k-\varepsilon$, e Turbulence 
Intensity and Length (TIL).

Portanto, testes de malha foram realizados envolvendo as duas possibilidades de modelo de turbulência comparando os resultados obtidos em cada um. Com base nesses testes foram definidos o nível de malha e o modelo de turbulência a serem considerados na análise comparativa entre as hélices.

As condições de contorno aplicadas ao problema, considerando o processo real de misturação, foram:

- Propriedades do fluido de trabalho que, da impossibilidade de se obter as propriedades do resíduo a ser misturado pela hélice, foram consideradas as propriedades da água a $25^{\circ} \mathrm{C}$;

- Entrada e saída do conduto consideradas como aberturas inicialmente à pressão atmosférica;

- Rotação de trabalho da hélice igual a 300 rpm no sentido horário de rotação.

Finalizada a montagem do procedimento para a análise computacional, a simulação foi executada de modo a obter a pressão média na saída da hélice, que em conjunto com a pressão atmosférica na entrada e a área de giro da mesma fornecem a força de empuxo quando em operação.

Como critério comparativo, este procedimento foi repetido para a simulação de uma hélice de dimensões semelhantes, porém com ângulo de inclinação das pás de $25^{\circ}$. Os ângulos de inclinação foram definidos com base em hélices já utilizadas em agitadores de resíduos de tanques biodigestores.

\section{ESTUDO DE MALHA}

Os resultados foram obtidos por simulação numérica com o intuito de se determinar a força de empuxo causada pela hélice quando em funcionamento.

Para a determinação da força de empuxo, foi considerada a pressão $p_{2}$ como sendo a pressão atmosférica (101325 Pa) devido à condição de fluido estacionário na entrada do duto. Portanto, toda a diferença de pressão causada no fluido desde a entrada do duto até a saída da hélice é causada pelo funcionamento da mesma. A área de disco, considerada nas simulações, foi de 0,2375 $\mathrm{m}^{2}$ tanto para a obtenção da força de empuxo quanto para a vazão mássica.

No desenvolvimento da análise numérica, optou-se por utilizar os tamanhos de malha padrão do software SolidWorks Flow Simulation respectivos aos níveis de 5 a 8 , sendo a malha de nível 5 a mais grosseira e a malha de nível 8 a mais refinada.

A primeira hélice testada apresenta um ângulo de inclinação das pás igual a $20^{\circ}$. Foi considerado, nessa primeira análise, o modelo de turbulência Turbulence Energy and Dissipation (TED) nos valores padrão do software, ou seja, o valor de 1 $\mathrm{J} / \mathrm{kg}$ para a energia turbulenta e $1 \mathrm{~W} / \mathrm{kg}$ para a dissipação turbulenta. A análise desta hélice, para os quatro tamanhos de malha, forneceu os seguintes resultados (Quadro 1):

Quadro 1: Resultados para as análises com o modelo de turbulência TED envolvendo os quatro níveis de tamanho de malha na hélice de $20^{\circ}$.

\begin{tabular}{|c|c|c|c|}
\hline Hélice 20 & $p_{3}(\mathrm{~Pa})$ & $\dot{m}(\mathrm{~kg} / \mathrm{s})$ & $F_{T}(\mathrm{~N})$ \\
\hline Malha 5 & 103897,050 & 190,125 & 611,075 \\
\hline Malha 6 & 103891,032 & 189,701 & 609,645 \\
\hline Malha 7 & 103897,169 & 190,127 & 611,103 \\
\hline Malha 8 & 103844,168 & 210,733 & 598,511 \\
\hline
\end{tabular}

Fonte: Autor (2019).

Pode-se observar, nesse caso, que a variação entre a maior e menor força de empuxo obtida é de $2,06 \%$, uma diferença relativamente pequena, o que demonstra a convergência do estudo. Já a vazão mássica média da seção apresentou uma variação de 9,98\%.

A segunda hélice analisada possui um ângulo de inclinação das pás igual a $25^{\circ}$ e foi testada sob as mesmas condições da primeira. Para esta hélice foram obtidos os seguintes resultados (Quadro 2):

Quadro 2: Resultados para as análises com o modelo de turbulência TED envolvendo os quatro níveis de tamanho de malha na hélice de $25^{\circ}$.

\begin{tabular}{|c|c|c|c|}
\hline Hélice $25^{\circ}$ & $p_{3}(\mathrm{~Pa})$ & $\dot{m}(\mathrm{~kg} / \mathrm{s})$ & $F_{T}(\mathrm{~N})$ \\
\hline Malha 5 & 105093,589 & 207,025 & 895,352 \\
\hline Malha 6 & 105172,934 & 206,833 & 914,203 \\
\hline Malha 7 & 105123,067 & 206,897 & 902,356 \\
\hline Malha 8 & 105192,697 & 228,889 & 918,899 \\
\hline
\end{tabular}

Fonte: Os Autores.

Pode-se observar que a variação entre a maior e a menor força de empuxo obtida é de $2,56 \%$, pouco maior do que a diferença obtida na hélice anterior. Já a vazão mássica média da seção 
apresentou uma variação de 9,64\%, menor do que a anterior.

A Figura 4 apresenta a diferença entre as duas hélices para o modelo de turbulência TED.

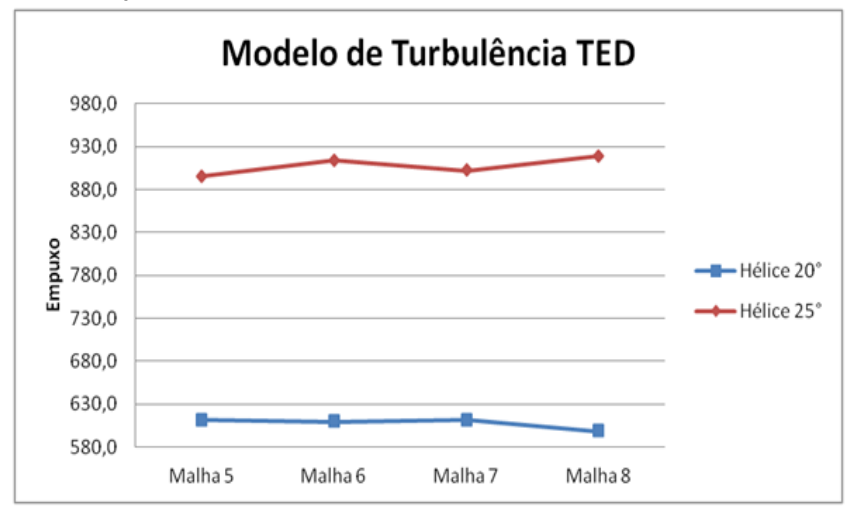

Figura 4: Gráfico comparativo da força de empuxo obtida nas duas hélices considerando o modelo de turbulência TED aplicado aos quatro níveis padrão de tamanho de malha.

Fonte: Os Autores.

Num modo geral, os resultados apresentados para as duas hélices apresentaram variações semelhantes, o que representa uma boa indicativa quando o critério baseia-se na comparação.

$O$ procedimento da análise anterior foi executado novamente considerando o modelo de turbulência Turbulence Intensity and Length (TIL) nos valores padrão do software, ou seja, $2 \%$ para a intensidade turbulenta e 0,0105 $\mathrm{m}$ para a escala de comprimento de turbulência. A análise da hélice com ângulo de inclinação de $20^{\circ}$, para os quatro tamanhos de malha, forneceu os seguintes resultados (Quadro 3):

Quadro 3: Resultados para as análises com o modelo de turbulência TIL envolvendo os quatro níveis de tamanho de malha na hélice de $20^{\circ}$.

\begin{tabular}{|c|c|c|c|}
\hline Hélice $20^{\circ}$ & $p_{3}(\mathrm{~Pa})$ & $\dot{m}(\mathrm{~kg} / \mathrm{s})$ & $F_{T}(\mathrm{~N})$ \\
\hline Malha 5 & 103986,015 & 193,382 & 632,212 \\
\hline Malha 6 & 104036,011 & 194,501 & 644,090 \\
\hline Malha 7 & 104036,012 & 194,501 & 644,090 \\
\hline Malha 8 & 104202,225 & 207,266 & 683,580 \\
\hline
\end{tabular}

Fonte: Os Autores.

Pode-se observar, nesse caso, que a variação entre a maior e menor força de empuxo obtida é de $7,51 \%$ e a variação para a vazão mássica média da seção é de $6,70 \%$. Em comparação com o modelo de turbulência TED a força de empuxo obteve uma diferença maior entre seus valores enquanto a diferença para os valores de vazão mássica diminuiu. É possível observar também que o principal responsável por esse acréscimo foi a análise executada com a malha de nível 8.

Para a hélice com ângulo de inclinação de $20^{\circ}$, nessas mesmas condições, obteve-se:

Quadro 4: Resultados para as análises com o modelo de turbulência TIL envolvendo os quatro níveis de tamanho de malha na hélice de $25^{\circ}$.

\begin{tabular}{|c|c|c|c|}
\hline Hélice $25^{\circ}$ & $p_{3}(\mathrm{~Pa})$ & $\dot{m}(\mathrm{~kg} / \mathrm{s})$ & $F_{T}(\mathrm{~N})$ \\
\hline Malha 5 & 105085,945 & 208,347 & 893,536 \\
\hline Malha 6 & 105014,725 & 209,827 & 876,616 \\
\hline Malha 7 & 105044,160 & 209,888 & 883,609 \\
\hline Malha 8 & 105060,098 & 228,838 & 887,395 \\
\hline
\end{tabular}

Fonte:Os Autores.

Pode-se observar que a variação entre a maior e menor força de empuxo obtida é de 1,89\%, bem menor do que a diferença obtida na hélice anterior. Já a vazão mássica média da seção apresentou uma variação de $8,95 \%$, aumentando sua diferença em relação à hélice com ângulo de inclinação de $20^{\circ}$.

A Figura 5 apresenta a diferença entre as duas hélices para o modelo de turbulência TIL.

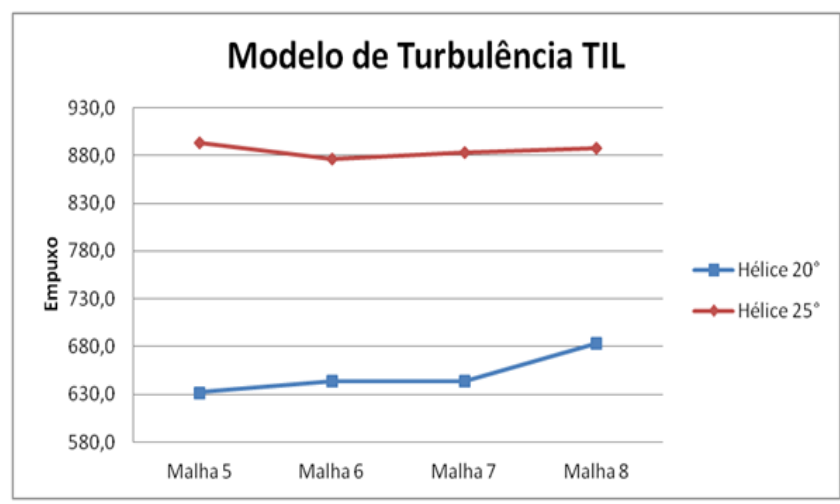

Figura 5: Gráfico comparativo da força de empuxo obtida nas duas hélices considerando o modelo de turbulência TIL aplicado aos quatro níveis padrão de tamanho de malha.

Fonte: Os Autores.

Este gráfico evidencia que a análise realizada com a malha de nível 8 foi a grande responsável pelo aumento da variação percentual da força empuxo na hélice de $20^{\circ}$.

A Figura 6 apresenta a comparação entre as forças de empuxo obtidas variando apenas 0 modelo de turbulência aplicado na hélice de $20^{\circ}$. 


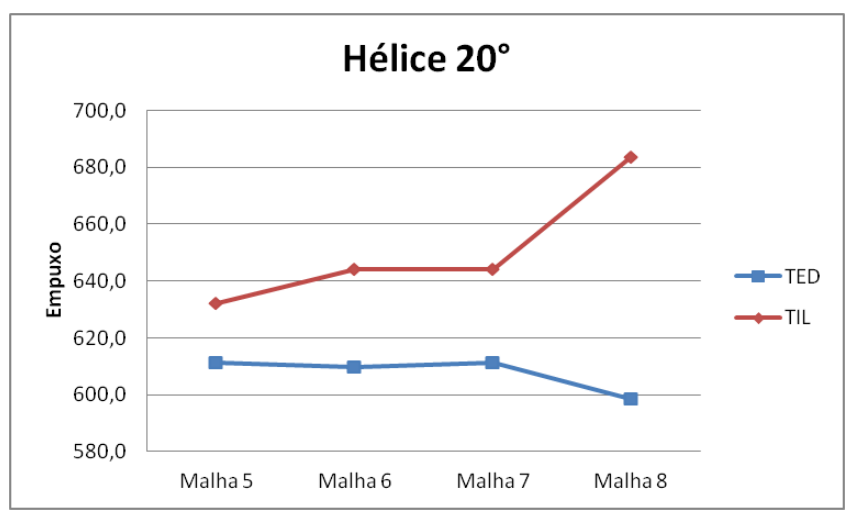

Figura 6: Gráfico comparativo da força de empuxo obtida na hélice de $20^{\circ}$ considerando os modelos de turbulência TED e TIL, aplicados aos quatro níveis padrão de tamanho da malha.

Fonte: Os Autores.

Pode-se observar que há uma diferença considerável entre os resultados obtidos para cada modelo de turbulência considerando a mesma malha. A maior diferença obtida foi para a malha 8, apresentando o menor valor de empuxo no modelo TED e o maior valor de empuxo no modelo TIL.

$\mathrm{Na}$ Figura 7, para a hélice de $25^{\circ}$, pode-se observar que ambos os modelos de turbulência apresentaram resultados semelhantes para a malha 5 e oscilaram nas análises para as outras malhas.

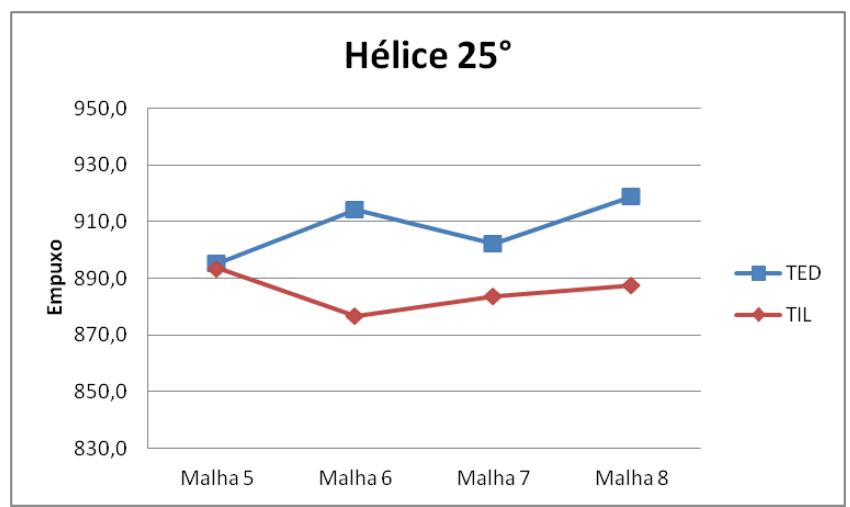

Figura 7: Gráfico comparativo da força de empuxo obtida na hélice de $25^{\circ}$ considerando os modelos de turbulência TED e TIL aplicados aos quatro níveis padrão de tamanho de malha.

Fonte: Os Autores.

Assim, pode-se concluir que o modelo de turbulência aplicado na análise apresenta significativa influência no resultado obtido. Portanto, deve-se escolher o modelo de turbulência adequado para cada tipo de análise.
A variação da força de empuxo entre as hélices, considerando os dois modelos de turbulência, são apresentados nos Quadros 5 e 6.

Quadro 5: Comparação da força de empuxo obtida em ambas as hélices com o modelo de turbulência TED envolvendo os quatro níveis de tamanho de malha.

\begin{tabular}{|c|c|c|c|}
\hline TED & $F_{T}(\mathrm{~N})-20^{\circ}$ & $F_{T}(\mathrm{~N})-25^{\circ}$ & Variação \\
\hline Malha 5 & 611,1 & 895,4 & $32 \%$ \\
\hline Malha 6 & 609,6 & 914,2 & $33 \%$ \\
\hline Malha 7 & 611,1 & 902,4 & $32 \%$ \\
\hline Malha 8 & 598,5 & 918,9 & $35 \%$ \\
\hline
\end{tabular}

Fonte: Autor (2019).

A variação média da força de empuxo entre as hélices, para o modelo de turbulência TED, é de aproximadamente $33 \%$. Enquanto que a variação média, apresentada no Quadro 6, para o modelo TIL é de $26 \%$.

Quadro 6: Comparação da força de empuxo obtida em ambas as hélices com o modelo de turbulência TIL envolvendo os quatro níveis de malha.

\begin{tabular}{|c|c|c|c|}
\hline TIL & $F_{T}(\mathrm{~N})-20^{\circ}$ & $F_{T}(\mathrm{~N})-25^{\circ}$ & Variação \\
\hline Malha 5 & 632,2 & 893,5 & $29 \%$ \\
\hline Malha 6 & 644,1 & 876,6 & $27 \%$ \\
\hline Malha 7 & 644,1 & 883,6 & $27 \%$ \\
\hline Malha 8 & 683,6 & 887,4 & $23 \%$ \\
\hline
\end{tabular}

Fonte: Autor (2019).

O gráfico comparativo das variações é apresentado na Figura 8.

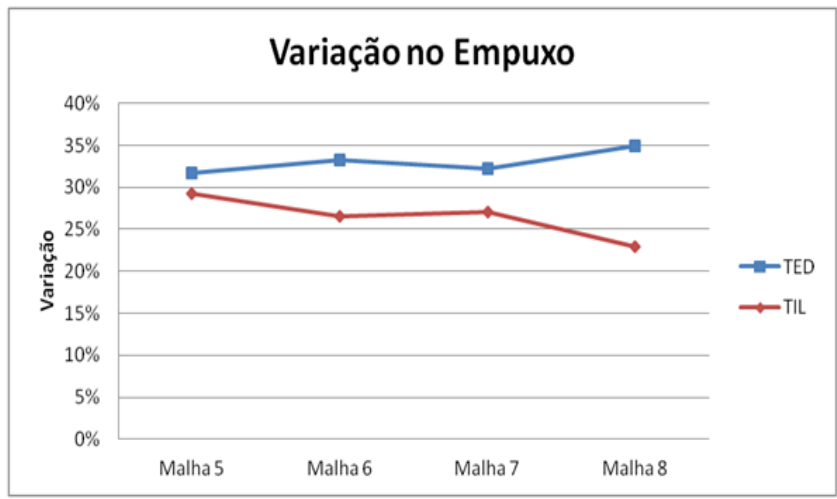

Figura 8: Gráfico comparativo da variação da força de empuxo obtida nas duas hélices considerando os modelos de turbulência TED e TIL aplicados aos quatro níveis padrão de tamanho de malha.

Fonte: Os Autores. 


\section{RESULTADOS}

Após a realização do estudo de malha para ambas as hélices, considerando também os dois modelos de turbulência disponíveis no software, a malha de nível 7 e o modelo de turbulência TED foram selecionados, pois se mostraram melhores tanto na obtenção da solução quanto no tempo de processamento da simulação.

O ângulo de inclinação das pás da primeira hélice testada é $20^{\circ}$. A força de empuxo obtida nesse caso foi de $611,103 \mathrm{~N}$, com uma vazão mássica média de fluido escoando pela área de seção transversal de saída da hélice de 190,127 $\mathrm{kg} / \mathrm{s}$.

A segunda hélice analisada possui um ângulo de inclinação das pás igual a $25^{\circ}$ e foi testada sob as mesmas condições da primeira. Para esta hélice, a força de empuxo gerada foi de 902,356 $\mathrm{N}$ com uma vazão mássica média da hélice de $206,897 \mathrm{~kg} / \mathrm{s}$.

Pode-se observar que a hélice com ângulo de inclinação de $25^{\circ}$ produz, aproximadamente, $32 \%$ mais empuxo e apresenta vazão mássica $8 \%$ maior do que a hélice com ângulo de inclinação de $20^{\circ}$. Isso pode ser visto na comparação dos campos de velocidades da Figura 9.

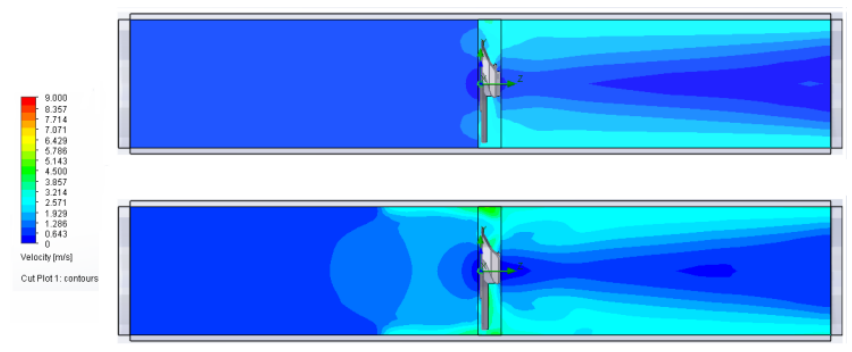

Figura 9: Comparação entre os campos de velocidade das hélices de $20^{\circ}$ e $25^{\circ}$ respectivamente, considerando na análise o modelo de turbulência TED e malha 7. Fonte: Os Autores.

Os campos de velocidades, da Figura 9, são consequência do funcionamento das hélices. A comparação entre as linhas de fluxo produzidas por cada hélice pode ser observada na Figura 10.

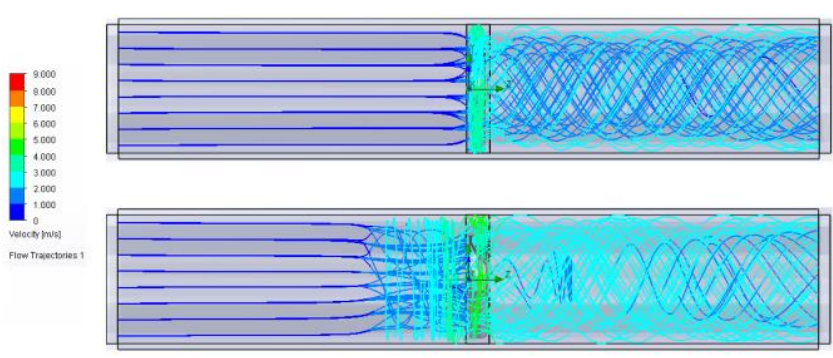

Figura 10: Comparação entre as linhas de fluxo das hélices de $20^{\circ}$ e $25^{\circ}$ respectivamente, considerando na análise o modelo de turbulência TED e malha 7.

Fonte: Os Autores.

Dessa forma, pode-se concluir que a força de empuxo gerada pela hélice com ângulo de inclinação de $25^{\circ}$ é maior e tem efeito significativo, também, na região anterior à hélice. Portanto, em se tratando de aumento na produção de biogás, a hélice com maior ângulo de inclinação se mostra mais eficiente, pois promove uma melhor misturação dos resíduos no tanque biodigestor.

\section{CONCLUSÃO}

A partir da análise dos resultados obtidos neste trabalho, é possível inferir as seguintes conclusões:

Primeiramente, o processo de simplificação geométrica do projeto de cada hélice, removendo recursos que são insignificantes na análise, foi necessário para reduzir erros de construção de malha e, assim, diminuir o tempo de processamento computacional e auxiliar na convergência do problema.

O estudo de simulação numérica de ambas as hélices, executado para a obtenção da força de empuxo gerada, foi realizado com 4 níveis diferentes de tamanho de malha e dois modelos de turbulência distintos, totalizando 16 simulações. Dentre os testes desenvolvidos, os que apresentaram melhor desempenho foram os realizados para a malha de nível 7 e modelo de turbulência TED. Com isso, foi possível determinar que a hélice com ângulo de inclinação de $25^{\circ}$ produz, aproximadamente, $32 \%$ mais empuxo e apresenta vazão mássica $8 \%$ maior do que a hélice com ângulo de inclinação de $20^{\circ}$. Portanto, em se tratando de aumento na produção de biogás, a hélice com maior ângulo de inclinação se mostra mais eficiente, pois promove uma melhor misturação dos resíduos no tanque biodigestor.

Como o software SolidWorks Flow Simulation apresenta apenas dois modelos de turbulência e 
opções restritas de configuração de malha, os ensaios servem apenas com critério comparativo entre as hélices, não representando o valor real da força de empuxo, vazão ou pressões.

\section{REFERÊNCIAS}

[1] BUENO, R. de F. Comparação entre biodigestores operados em escala piloto para produção de biogás alimentado com estrume bovino. HOLOS Environment, São Paulo, v. 10, n. 1, p. 111-125, 2010. Disponível em: https://www.ceaunesp.org.br/holos/article/download/2547/3422. Acesso em: 16 out. 2018.

[2] PELLIZZER, E. L. Otimização da produção de biogás utilizando aquecimento e agitação com automação de biodigestores. 2017. $56 \mathrm{f}$. Dissertação (Mestrado em Engenharia) Universidade Estadual do Oeste do Paraná, Cascavel, 2017. Disponível em:

http://tede.unioeste.br/handle/tede/3021. Acesso em: 25 out. 2018.

[3] FOX, R. W.; PRITCHARD, P. J.; MCDONALD, A. T. Introdução à mecânica dos fluidos. Tradução de Ricardo Nicolau Nassar Koury, Luiz Machado. 8. ed. Rio de Janeiro: LTC, 2014.

[4] PINHEIRO, T. P. Obtenção de Torque e Empuxo de Propulsores através do Uso de Sistema de Medição de Eixo por Telemetria. 2014. 52 f. Dissertação (Projeto de Graduação) Universidade Federal do Rio de Janeiro, Rio de Janeiro, 2014. Disponível em: monografias.poli.ufrj.br/monografias/monopoli10 010448.pdf. Acesso em: 24 out. 2018. 